\title{
Evaluation of sagittal airway dimensions after face mask therapy with rapid maxillary expansion in Class III growing patients
}

\author{
Elisabetta Cretella Lombardo ${ }^{\mathrm{a}, *}$, Lorenzo Franchi ${ }^{\mathrm{b}, \mathrm{c}}$, Roberta Lione ${ }^{\mathrm{a}}$, Alice Chiavaroli ${ }^{\mathrm{a}}$, \\ Paola Cozza ${ }^{\mathrm{a}, \mathrm{d}}$, Chiara Pavoni ${ }^{\mathrm{a}}$ \\ a Department of Clinical Sciences and Translational Medicine, University of Rome Tor Vergata, Italy \\ ${ }^{\mathrm{b}}$ Department of Surgery and Translational Medicine, University of Florence, Florence, Italy \\ ${ }^{\mathrm{c}}$ Thomas M. Graber Visiting Scholar, Department of Orthodontics and Pediatric Dentistry, School of Dentistry, The University of Michigan, Ann Arbor, MI, USA \\ ${ }^{\mathrm{d}}$ Department of Orthodontics, University Zoja e Këshillit Të Mirë, Tirane, Albania
}

\section{A R T I C L E I N F O}

\section{Keywords:}

Class III malocclusion

Airway

Growing patients

\begin{abstract}
A B S T R A C T
Objective: The aim of this investigation was to analyze the effects of RME and FM on the airway dimensions in Class III patients compared with untreated controls.

Methods: A sample of 47 Class III patients treated with RME and FM was analyzed. The treated group was compared with 18 untreated controls. Lateral cephalograms for each patient at T1, T2, and T3 were digitized. Results: At long-term evaluation a significant increase in airway size and a significant decrease in adenoid size were found in the treated group as well as an improvement in the pharynx dimension. During active treatment the treated group showed a significant improvement in lower airway size and in lower pharynx dimension. A significant decrease in adenoid size was also found.

Conclusion: The treatment with RME and FM produced favorable stable changes in the airway dimensions in Class III subjects when compared with untreated controls.
\end{abstract}

\section{Introduction}

Class III malocclusions are considered to be among the most challenging malocclusions to treat $[1,2]$. Studies on the multifactorial etiology of Class III malocclusions have shown that true maxillary skeletal retrusion is as frequent as mandibular prognathism and that $32-63 \%$ of patients with a skeletal Class III malocclusion have a retruded maxilla or a combination of a retruded maxilla and excessive mandibular growth [2]. Possible approaches include fixed appliances, removable appliances, removable functional appliances, chin cup, protraction headgear, and skeletal anchorage systems, or a combination of multiple of these treatment modalities [3]. The skeletal and dentoalveolar effects of orthopedic treatment in subjects with Class III malocclusions with maxillary retrognathia, have been well documented in the orthodontic literature $[4,5]$.

In growing patients, maxillary protraction with a face mask (FM) following rapid maxillary expansion (RME) has been proven to produce favorable changes in Class III malocclusions by anterior displacement of the maxilla and a control of mandibular growth with upward and forward direction of condylar growth [6]. A skeletal change that can occur from orthopedic treatment of Class III malocclusion is the alteration of the size of airway $[7,8]$. Several studies [6,9-11] evaluated the effects of FM appliances with or without rapid maxillary expansion (RME) on the oropharyngeal and nasopharyngeal dimensions with controversial results. The major limitation of all these studies is the short-term nature of the observations.

The aim of this investigation was to analyze the effects of RME and FM combined with bite block appliance in the lower arch (BB), on the nasopharyngeal and oropharyngeal sagittal airway dimensions in subjects with dentoskeletal Class III malocclusions compared with an untreated Class III control group.

\section{Methods}

A sample of 47 patients (22 females and 25 males) with Class III malocclusion treated with either bonded or banded RME with a mandibular removable Bite Block (BB) appliance followed by FM therapy was analyzed. The subjects were collected from the records of patients treated consecutively at the Department of Orthodontics of the University of Rome Tor Vergata and of the University of Florencefrom 2006 to 2014. The study project was approved by the Ethical Committee at the University of Rome Tor Vergata, and informed

\footnotetext{
* Corresponding author. Department of Clinical Sciences and Translational Medicine, University of Rome Tor Vergata, Viale Oxford 81, 00133, Rome, Italy.

E-mail address: eclomb@icloud.com (E. Cretella Lombardo).
} 
consent was obtained from the subjects' parents (protocol number 168/ 17). All patients had the following dentoskeletal features before therapy (T1) when the pretreatment lateral cephalogram was taken: European ancestry (white), anterior crossbite or edge-to-edge incisor relationship, Class III molar relationship, Wits appraisal of $-2.0 \mathrm{~mm}$ or less, no discrepancy between centric occlusion and centric relation (indicating pseudo-Class III malocclusion), and prepubertal skeletal maturation (CS 1-CS 3) [12], no comorbidities associated, and absence of adenotonsillectomy.

Lateral cephalograms were taken before treatment (T1), at the end of active treatment with RME and FM (T2), and at long-term observation (T3) after completion of growth. The T3 observations were collected and analyzed regardless of the treatment outcomes in terms of correction of Class III malocclusion in the individual patients. This approach assisted in further reducing potential selection bias of the study.

The treated group was compared with an untreated Class III control group of 18 subjects ( 9 females, 9 males) selected from the records at the Department of Orthodontics of the University of Florence and from the American Association of Orthodontists Foundation Craniofacial Growth Legacy Collection (http://www.aaoflegacycollection.org, Bolton Brush Growth Study, Michigan Growth Study, Denver Growth Study, Oregon Growth Study, and Iowa Growth Study). The control group matched the treated group as to type of dentoskeletal disharmony, chronologic age at T1, T2 and T3 duration observation interval, skeletal maturation at $\mathrm{T} 1, \mathrm{~T} 2$ and $\mathrm{T} 3$, and gender distribution. The controls presented the same inclusion criteria of the treated group. Demographic data of the samples were reported in Table 1.

The 3 components of the RME/FM therapy used in this study were a maxillary expansion appliance (either banded or bonded), a facemask, and a bite block in the lower arch. Patients treated with the bonded RME (Fig. 1) received an acrylic splint expander with splints extending from the deciduous canine to the second deciduous molar [13]. Patients treated with a banded RME (Fig. 2) received a butterfly expander with bands either on second deciduous molars or on the first permanent molars [14]. For both appliance designs, vestibular hooks were present at the level of the deciduous canines. Patients' parents of both groups were instructed to activate the palatal expander $1 / 4$ of a turn per day until overcorrection of the transverse width was achieved (palatal cusps of the upper posterior teeth approximating the buccal cusps of the lower posterior teeth) [15]. At the end of active expansion, patients were given FM (Fig. 3). The patients were instructed to wear the FM at least $14 \mathrm{~h}$ per day. All patients were treated at least to a positive dental overjet before discontinuing treatment; most patients were overcorrected toward a Class II occlusal relationship [6]. In patients treated with a banded RME, a removable BB appliance was used full-time during FM treatment. The BB appliance (Fig. 4) was constructed in the form of a Schwarz plate for the lower arch with a vestibular arch, occlusal resin splints, and an expansion screw that was activated when needed [9]. The splints were used to control molar eruption, control intermaxillary divergence, and prevent clockwise mandibular rotation. The patients were instructed to wear the BB $24 \mathrm{~h}$ a day, including during meals; cooperation was good for all subjects.

Table 1

Demographics.

\begin{tabular}{lllll}
\hline & \multicolumn{2}{l}{ Treated Group } & \multicolumn{2}{l}{ Control Group } \\
\cline { 2 - 5 } & Mean & SD & Mean & SD \\
\hline Age T1 (years) & 7.8 & 1.5 & 8.9 & 0.8 \\
Age T2 (years) & 9.8 & 1.9 & 11.0 & 1.2 \\
Age T3 (years) & 15.2 & 2.4 & 16.2 & 1.2 \\
T1-T2 interval (years) & 2.0 & 0.9 & 2.1 & 0.8 \\
T2-T3 interval (years) & 5.4 & 1.9 & 5.3 & 2.0 \\
T1-T3 interval (years) & 7.4 & 1.8 & 7.3 & 1.5 \\
\hline
\end{tabular}

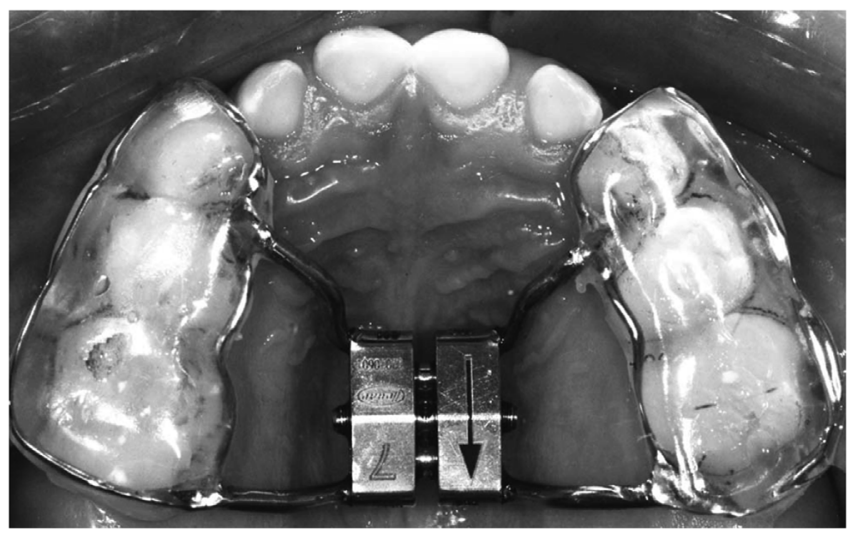

Fig. 1. Occlusal view of bonded maxillary expander.

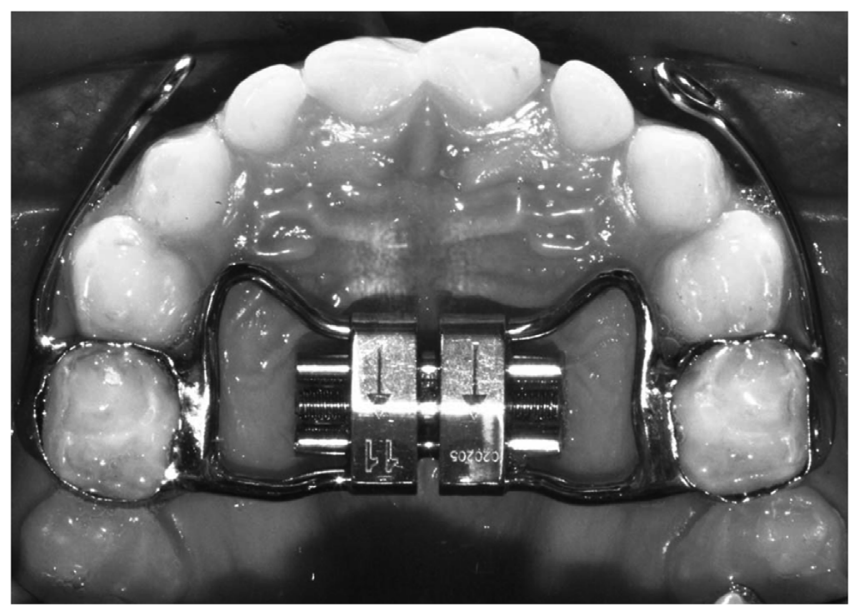

Fig. 2. Occlusal view of banded maxillary expander.
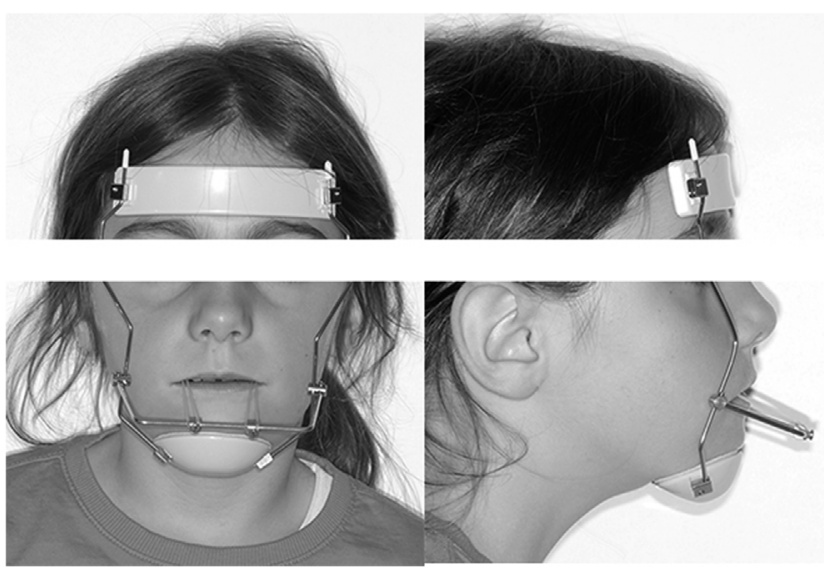

Fig. 3. Extraoral view of Facemask.

Forces of about $600 \mathrm{~g}$ per side were used during protraction therapy. Cooperation was good for all patients [9]. The T1 to T2 interval comprised active therapy followed by 6-9 months of post-treatment with removable mandibular retractor at the maxillary arch.

\subsection{Cephalometric analysis}

All lateral cephalograms were hand traced at a single sitting. Cephalograms were traced by one investigator. Landmark location and the accuracy of the anatomical outlines were verified by a second. Any discrepancies as to landmark placement were resolved by mutual 


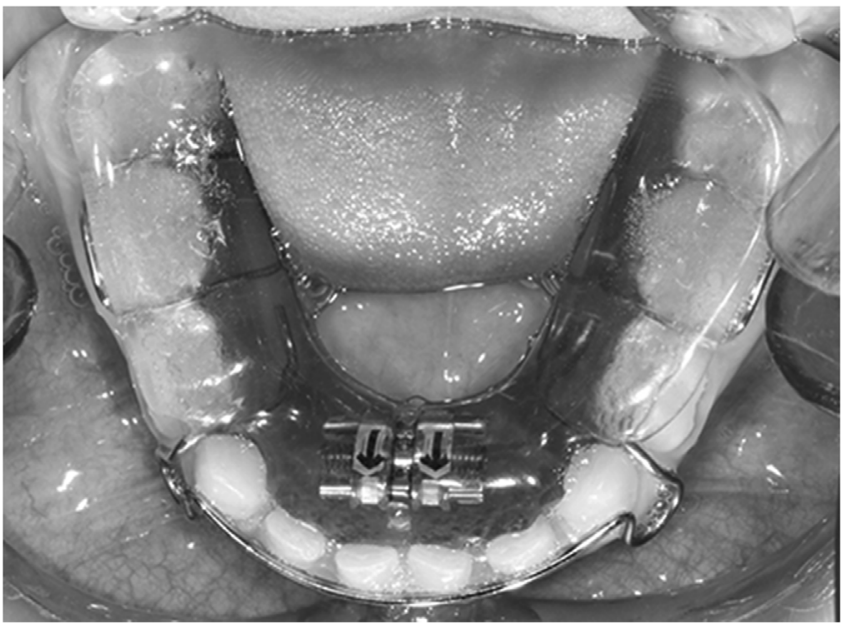

Fig. 4. Occlusal view of Bite Block appliance.

agreement. A customized digitization regimen (Viewbox, version 4.0, dHAL Software, Kifissia, Greece) was created and used for the cephalometric evaluation.

Lateral cephalograms for each patient at T1, T2, and T3 were digitized, and a custom cephalometric analysis was used. Six linear variables were generated for each tracing.

The cephalometric measurements used were [16,17] (Fig. 5):

1. PNS-AD1: lower airway dimension; distance from PNS to the nearest adenoid tissue measured through the PNS-Ba line (AD1).

2. AD1-Ba: lower adenoid size; defined as the soft tissue thickness at the posterior nasopharynx wall through the PNS-Ba line.

3. PNS-AD2: upper airway dimension; distance from PNS to the nearest adenoid tissue measured through a perpendicular line to $\mathrm{S}-\mathrm{Ba}$ from PNS (AD2).

4. AD2-H: upper adenoid size; defined as the soft tissue thickness at the posterior nasopharynx wall through the PNS-H line $(\mathrm{H}$, Hormion, point located at the intersection between the perpendicular line to S-Ba from PNS and the cranial base).

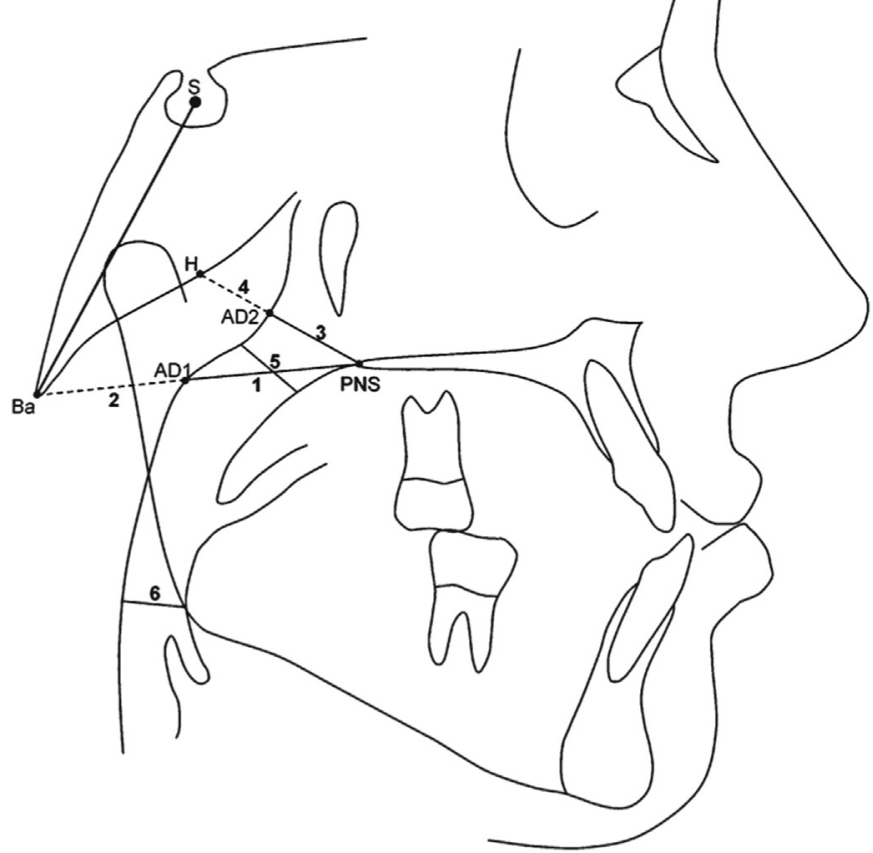

Fig. 5. Cephalometric measurements for the analysis of airway dimensions.
5. McNamara's upper pharynx dimension: the minimum distance between the upper soft palate and the nearest point on the posterior pharynx wall.

6. McNamara's lower pharynx dimension: the minimum distance between the point where the posterior tongue contour crosses the mandible and the nearest point on the posterior pharynx wall.

\subsection{Statistical analysis}

The primary aim of this study was to evaluate the long-term effects of RME and FM on the upper airways. Therefore, between-group comparisons were calculated for the craniofacial starting forms at T1 and for the T1-T3 changes. As secondary outcomes, between-group comparisons for the T1-T2 and T2-T3 changes also were performed. Descriptive statistics were calculated for all the cephalometric measurements in the two groups at T1, for the T1-T2, T2-T3, and T1-T3 changes. All data were normally distributed (Shapiro-Wilks' test). Between-group differences were tested with independent sample $t$ tests at T1 (baseline characteristics) and for the T1-T3, T1-T2, and T2-T3 changes. Since no study in the literature investigating the long-term effects of functional appliances on the airway dimensions was available, the power of the study was calculated for an effect size of 1.0 for the primary outcome variable PNS-AD2, with an alpha level of 0.05 .

As for the method error, 10 subjects from the final samples (30 cephalograms) were selected at random. All films were retraced and digitized a second time after 15 days by the same observer. The systematic and random errors for the cephalometric variables were analyzed with the paired $t$-test and Dahlberg's formula, respectively.

\section{Results}

No systematic error was detected for any of the variables. The error for linear measurements ranged from $0.40 \mathrm{~mm}$ (McNamara's lower pharynx dimension) to $0.68 \mathrm{~mm}$ (PNS-AD2). Statistical comparisons of the starting forms are reported in Table 2. Descriptive statistics and comparisons of the T1-T3, T1-T2, and T2-T3 changes between treated and untreated control groups are reported in Tables 3-5. In the longterm evaluation (T1-T3; Table 3), a significant increase in both lower and upper airway size (PNS-AD1; PNS-AD2) and a significant decrease in the upper and lower adenoid size (AD2-H; AD1-Ba) were present in the treated group as well as significant increases in the upper and lower pharynx dimensions.

During active treatment (T1-T2; Table 4), the treated group showed a significant increase in lower airway size (PNS-AD2), as well as a significant increase in the lower pharynx dimension. A significant decrease in the upper adenoid size (AD2-H) and in lower adenoid size (AD1-Ba) was also found. No statistically significant differences were observed for any of the other analyzed variables. Additional significant differences between the treated and the control group were also found

Table 2

Descriptive statistics and statistical comparisons (independent-samples t tests) of the starting forms (cephalometric values at T1).

\begin{tabular}{|c|c|c|c|c|c|c|c|c|}
\hline \multirow[t]{2}{*}{ Variables } & \multicolumn{2}{|c|}{$\begin{array}{l}\text { Treated } \\
\text { Group }\end{array}$} & \multicolumn{2}{|c|}{ Control Group } & \multirow[t]{2}{*}{ Diff. } & \multirow[t]{2}{*}{$P$ value } & \multicolumn{2}{|c|}{$\begin{array}{l}95 \% \text { CI of the } \\
\text { difference }\end{array}$} \\
\hline & Mean & SD & Mean & SD & & & Lower & Upper \\
\hline $\begin{array}{c}\text { Upper pharynx } \\
\text { dimension }\end{array}$ & 8.7 & 2.8 & 9.7 & 2.7 & -1.0 & 0.182 & -2.6 & 0.5 \\
\hline PNS-AD2 & 12.3 & 3.0 & 13.9 & 3.0 & -1.6 & 0.051 & -3.3 & 0.0 \\
\hline PNS-AD1 & 15.6 & 3.3 & 16.3 & 3.1 & -0.7 & 0.725 & & \\
\hline $\begin{array}{l}\text { Lower } \\
\text { pharynx } \\
\text { dimension }\end{array}$ & 13.3 & 2.8 & 11.5 & 2.9 & 1.8 & 0.019 & 0.3 & 3.4 \\
\hline AD2-H & 16.6 & 3.3 & 15.4 & 3.7 & 1.2 & 0.222 & -0.7 & 3.1 \\
\hline $\mathrm{AD} 1-\mathrm{Ba}$ & 24.1 & 4.2 & 20.1 & 3.8 & 4.0 & 0.001 & 1.7 & 6.3 \\
\hline
\end{tabular}


Table 3

Descriptive statistics and statistical comparisons (independent-samples t tests) of the T1-T3 changes in the Treated Group vs the Control Group.

\begin{tabular}{|c|c|c|c|c|c|c|c|c|}
\hline \multirow[t]{2}{*}{ Variables } & \multicolumn{2}{|c|}{$\begin{array}{l}\text { Treated } \\
\text { Group }\end{array}$} & \multicolumn{2}{|c|}{ Control Group } & \multirow[t]{2}{*}{ Diff. } & \multirow[t]{2}{*}{$P$ value } & \multicolumn{2}{|c|}{$\begin{array}{l}95 \% \mathrm{CI} \text { of the } \\
\text { difference }\end{array}$} \\
\hline & Mean & SD & Mean & SD & & & Lower & Upper \\
\hline $\begin{array}{l}\text { Upper } \\
\text { pharynx } \\
\text { dimension }\end{array}$ & 4.4 & 3.0 & 1.9 & 3.2 & 2.5 & 0.005 & 0.8 & 4.2 \\
\hline PNS-AD2 & 4.1 & 3.4 & -0.9 & 3.6 & 5.0 & 0.000 & 3.0 & 6.9 \\
\hline PNS-AD1 & 5.9 & 4.0 & 2.0 & 4.0 & 4.0 & 0.001 & 1.7 & 6.2 \\
\hline $\begin{array}{l}\text { Lower } \\
\text { pharynx } \\
\text { dimension }\end{array}$ & 2.6 & 3.6 & -1.1 & 2.6 & 3.7 & 0.000 & 1.8 & 5.5 \\
\hline AD2-H & -2.4 & 3.5 & 0.2 & 3.7 & -2.6 & 0.011 & -4.6 & -0.6 \\
\hline AD1-Ba & -3.2 & 3.8 & 0.2 & 4.1 & -3.4 & 0.002 & -5.5 & -1.2 \\
\hline
\end{tabular}

Table 4

Descriptive statistics and statistical comparisons (independent-samples t tests) of the T1-T2 changes in the Treated Group vs the Control Group.

\begin{tabular}{|c|c|c|c|c|c|c|c|c|}
\hline \multirow[t]{2}{*}{ Variables } & \multicolumn{2}{|c|}{$\begin{array}{l}\text { Treated } \\
\text { Group }\end{array}$} & \multicolumn{2}{|c|}{ Control Group } & \multirow[t]{2}{*}{ Diff. } & \multirow[t]{2}{*}{$\mathrm{P}$ value } & \multicolumn{2}{|c|}{$\begin{array}{l}95 \% \mathrm{CI} \text { of the } \\
\text { difference }\end{array}$} \\
\hline & Mean & SD & Mean & SD & & & Lower & Upper \\
\hline $\begin{array}{l}\text { Upper } \\
\text { pharynx } \\
\text { dimension }\end{array}$ & 2.3 & 1.5 & 1.9 & 3.5 & 0.4 & 0.469 & -0.8 & 1.7 \\
\hline PNS-AD2 & 3.1 & 1.7 & 0.9 & 2.8 & 2.3 & 0.003 & & \\
\hline PNS-AD1 & 3.8 & 2.3 & 2.9 & 4.6 & 0.9 & 0.299 & -0.8 & 2.6 \\
\hline $\begin{array}{l}\text { Lower } \\
\text { pharynx } \\
\text { dimension }\end{array}$ & 3.2 & 1.6 & 0.8 & 1.6 & 2.5 & 0.000 & 1.6 & 3.4 \\
\hline AD2-H & -1.9 & 1.5 & -0.7 & 4.2 & -1.2 & 0.011 & & \\
\hline AD1-Ba & -3.3 & 2.2 & -0.9 & 4.9 & -2.4 & 0.008 & -4.1 & -0.6 \\
\hline
\end{tabular}

Table 5

Descriptive statistics and statistical comparisons (independent-samples t tests) of the T2-T3 changes in the Treated Group vs the Control Group.

\begin{tabular}{|c|c|c|c|c|c|c|c|c|}
\hline \multirow[t]{2}{*}{ Variables } & \multicolumn{2}{|c|}{$\begin{array}{l}\text { Treated } \\
\text { Group }\end{array}$} & \multicolumn{2}{|c|}{ Control Group } & \multirow[t]{2}{*}{ Diff. } & \multirow[t]{2}{*}{$\mathrm{P}$ value } & \multicolumn{2}{|c|}{$\begin{array}{l}95 \% \mathrm{CI} \text { of the } \\
\text { difference }\end{array}$} \\
\hline & Mean & SD & Mean & SD & & & Lower & Upper \\
\hline $\begin{array}{c}\text { Upper pharynx } \\
\text { dimension }\end{array}$ & 2.1 & 3.2 & 0.0 & 3.4 & 2.1 & 0.026 & 0.2 & 3.9 \\
\hline PNS-AD2 & 1.0 & 3.3 & -1.7 & 3.5 & 2.7 & 0.005 & 0.8 & 4.6 \\
\hline PNS-AD1 & 2.1 & 3.9 & -0.9 & 4.7 & 3.1 & 0.009 & 0.8 & 5.3 \\
\hline $\begin{array}{l}\text { Lower } \\
\text { pharynx } \\
\text { dimension }\end{array}$ & -0.7 & 4.0 & -1.9 & 3.2 & 1.2 & 0.267 & -0.9 & 3.3 \\
\hline AD2-H & -0.5 & 3.5 & 1.0 & 4.0 & -1.4 & 0.162 & -3.4 & 0.6 \\
\hline AD1-Ba & 0.1 & 2.8 & 1.1 & 3.0 & -1.0 & 0.214 & -2.6 & 0.6 \\
\hline
\end{tabular}

in the T2-T3 interval (Table 5) with a significant increase of the upper pharynx dimension and of the upper and lower airway dimension (PNSAD1; PNS-AD2).

\section{Discussion}

The present study evaluated the treatment and post-treatment effects produced by orthopedic therapy of Class III malocclusion by means of RME and FM with special regard to the sagittal oropharyngeal and nasopharyngeal airway dimensions. The literature reports contrasting findings with regard to the possibility of improving the sagittal airway dimensions by means of maxillary protraction and a few studies evaluated the effects of maxillary protraction combined with maxillary expansion $[2,6]$.
The features of the present investigation were:

1. The study evaluated both active and post-treatment outcomes, with a long-term observation.

2. A group of 18 subjects with untreated Class III malocclusions was used as a longitudinal control sample for both active treatment and post-treatment periods.

3. All subjects in both treated and control groups were at a prepubertal stage in skeletal development at initial observation and at postpubertal stage at the final observation.

The results of the present study revealed significant favorable effects of RME and FM therapy in the oro- and nasopharyngeal sagittal airway dimensions in subjects with Class III malocclusion when compared with untreated Class III controls. During active treatment the treated group showed a significant increment in the lower airway size (PNS-AD2) and in the lower pharynx dimension. Moreover, a significant decrease in the upper adenoid size (AD2-H) and in the lower adenoid size (AD1-Ba) was also found.

In agreement with our study, a recent systematic review and metaanalysis [18] on the efficacy of maxillary protraction on improving pharyngeal airway dimensions in growing Class III patients, indicated that maxillary protraction appliances can increase pharyngeal airway dimensions in the short term. In the literature there is a lack of longterm observations of the airway dimensions after treatment with orthopedic appliances. This kind of follow-up is necessary to determine the stability of this type of treatments before, during, and after the growth peak. In the current study the favorable changes obtained during active treatment were maintained at a long-term observation after puberty with an additional improvement occurring during the T2T3 interval.

In the meta-analysis cited above [18], 6 studies (168 treated subjects and 140 untreated controls) were included in the final quantitative synthesis and they were all of high-quality level. Compared to untreated control groups, the treatment groups showed significant increases in the nasopharyngeal airway dimensions and McNamara's upper pharynx dimension. The orthopedic effects might produce an anterior displacement of point PNS [19] which could move the soft palate forwards thus leading to an increase of the post-palatal airway dimension. Additionally, because of the anterior displacement of the maxilla, there were significant improvements in the nasopharyngeal airway dimensions, including its thickness and area (PNS-AD1, PNS-AD2, aerial nasopharyngeal area and total nasopharyngeal area) [18].

However, in disagreement with what observed in our study, no statistically significant differences were observed in the adenoidal nasopharyngeal area and McNamara's lower pharynx dimension [18]. This could be attributed to the fact that all the patients included in our study underwent rapid maxillary expansion before maxillary protraction. The widening of the nasal cavity base, found after midpalatal suture opening in growing patients, allows for the reduction in nasal airway resistance and improvement in the respiratory pattern [20,21]. The significant improvement of the oro-nasopharyngeal dimensions that remains stable in the long term suggests a fundamental role of dentofacial orthopedics in the treatment of not only skeletal problem but also of constrictions of the oro-nasopharyngeal spaces during childhood [22].

\section{Conclusions}

The findings of the present study demonstrated the followings:

1. Treatment with RME followed by FM therapy was associated with significant favorable changes during active treatment (T1-T2) in the oro- and nasopharyngeal sagittal airway dimensions in subjects with Class III malocclusion when compared with untreated controls.

2. The advantageous changes obtained during T1-T2 interval were 
maintained in the long-term observation after puberty (T1-T3 interval) with additional favorable changes that occurred during the growth in the T2-T3 period.

\section{Funding information}

This work received no external funding.

\section{Declaration of competing interest}

The authors have no competing interests.

\section{References}

[1] E. Onem Ozbilen, H.N. Yilmaz, N. Kucukkeles, Comparison of the effects of rapid maxillary expansion and alternate rapid maxillary expansion and constriction protocols followed by facemask therapy, Korean J. Orthod. 49 (2019) 49-58.

[2] A.S. Kilinç, S.G. Arslan, J.D. Kama, T. Ozer, O. Dari, Effects on the sagittal pharyngeal dimensions of protraction and rapid palatal expansion in Class III malocclusion subjects, Eur. J. Orthod. 30 (2008) 61-66.

[3] A. Al Taki, A. Thabit, Changes in pharyngeal airway dimensions, hyoid position, and head posture after rapid palatal expansion and face mask therapy, J. Am. Sci. 10 (2014).

[4] K. Sayinsu, F. Isik, T. Arun, Sagittal airway dimensions following maxillary protraction: a pilot study, Eur. J. Orthod. 28 (2006) 184-189.

[5] L. Franchi, C. Pavoni, S. Cerroni, P. Cozza, Thin-plate spline analysis of mandibular morphological changes induced by early class III treatment: a long-term evaluation, Eur. J. Orthod. 36 (2014) 425-430.

[6] M. Mucedero, T. Baccetti, L. Franchi, P. Cozza, Effects of maxillary protraction with or without expansion on the sagittal pharyngeal dimensions in Class III subjects, Am. J. Orthod. Dentofacial Orthop. 135 (2009) 777-781.

[7] S. Hiyama, N. Suda, M.I. Suzuki, S. Tsuiki, M. Ogawa, S. Suzuki, S. Suzuki, T. Kuroda, Effects of maxillary protraction on craniofacial structures and upper airway dimension, Angle Orthod. 72 (2002) 43-47.

[8] H. Oktay, E. Ulukaya, Maxillary protraction appliance effect on the size of the upper airway passage, Angle Orthod. 78 (2008) 209-213.
[9] T. Baccetti, L. Franchi, M. Mucedero, P. Cozza, Treatment and post-treatment effects of facemask therapy on the sagittal pharyngeal dimensions in Class III subjects, Eur. J. Orthod. 32 (2010) 346-350.

[10] M. Akin, F.I. Ucar, C. Chousein, Z. Sari, Effects of chincup or facemask therapies on the orofacial airway and hyoid position in Class III subjects, J. Orofac. Orthop. Der Kieferorthopadie 76 (2015) 520-530.

[11] B. BalosTuncer, C. Ulusoy, C. Tuncer, C. Turkoz, S. Kale Varlik, Effects of reverse headgear on pharyngeal airway in patients with different vertical craniofacial features, Braz. Oral Res. 29 (2015).

[12] T. Baccetti, L. Franchi, J.A. McNamara Jr., The cervical vertebral maturation (CVM) method for the assessment of optimal treatment timing in dentofacial orthopedics, Semin. Orthod. 11 (2005) 119-129.

[13] C. Pavoni, M. Mucedero, T. Baccetti, L. Franchi, A. Polimeni, P. Cozza, The effects of facial mask/bite block therapy with or without rapid palatal expansion, Prog. Orthod. 10 (2009) 20-28.

[14] P. Cozza, A. Giancotti, A. Petrosino, "Butterfly expander" in mixed dentition, J. Clin. Orthod. 33 (1999) 583-587.

[15] R. Lione, L.T. Huanca Ghislanzoni, E. Defraia, L. Franchi, P. Cozza, Bonded versus banded rapid palatal expander followed by facial mask therapy: analysis on digital dental casts, Eur. J. Orthod. 38 (2016) 217-222.

[16] J.A. McNamara Jr., A method of cephalometric evaluation, Am. J. Orthod. 86 (1984) 449-469.

[17] C. Pavoni, E. Cretella Lombardo, L. Franchi, R. Lione, P. Cozza, Treatment and posttreatment effects of functional therapy on the sagittal pharyngeal dimensions in Class II subjects, Int. J. Pediatr. Otorhinolaryngol. 101 (2017) 47-50.

[18] Y. Ming, Y. Hu, Of maxillary protraction appliances on airway dimensions in growing class III maxillary retrognathic patients: a systematic review and metaanalysis, Int. J. Pediatr. Otorhinolaryngol. 105 (2018) 138-145.

[19] S.C. Woon, B. Thiruvenkatachari, Early orthodontic treatment for Class III malocclusion: a systematic review and meta-analysis, Am. J. Orthod. Dentofacial Orthop. 151 (2017) 28-52.

[20] F. Lofaso, A. Coste, M.P. D'Ortho, F. Zerah Lancner, C. Delclaux, F. Goldenberg, Nasal obstruction as a risk factor for sleep apnoea syndrome, Eur. Respir. J. 16 (2000) 639-643.

[21] M.P. Villa, C. Malagola, J. Pagani, M. Montesano, A. Rizzoli, C. Guilleminault, R. Ronchetti, Rapid maxillary expansion in children with obstructive sleep apnea syndrome: 12-month follow-up, Sleep Med. 8 (2007) 128-134.

[22] J.A. McNamara Jr., R. Lione, L. Franchi, F. Angelieri, L.H. Cevidanes, M.A. Darendeliler, P. Cozza, The role of rapid maxillary expansion in the promotion of oral and general health, Prog. Orthod. 16 (2015) 33. 